\title{
Effects of Anti-Cancer Drug Sensitivity-Related Genetic Differences on Therapeutic Approaches in Refractory Papillary Thyroid Cancer
}

\author{
Hyeok Jun Yun ${ }^{1,+} \mathbb{D}$, Minki Kim ${ }^{2,+}$, Sang Yong $\mathrm{Kim}^{3}{ }^{\text {, Sungsoon Fang }}{ }^{2} \mathbb{D}$, Yonjung Kim ${ }^{4}$, Hang-Seok Chang ${ }^{1}$, \\ Ho-Jin Chang ${ }^{1, *}$ and Ki Cheong Park ${ }^{3, * \mathbb{D}}$
}

check for updates

Citation: Yun, H.J.; Kim, M.; Kim, S.Y.; Fang, S.; Kim, Y.; Chang, H.-S.; Chang, H.-J.; Park, K.C. Effects of Anti-Cancer Drug Sensitivity-Related Genetic Differences on Therapeutic Approaches in Refractory Papillary Thyroid Cancer. Int. J. Mol. Sci. 2022, 23, 699. https://doi.org/10.3390/ ijms23020699

Academic Editor: Prasoon Agarwal

Received: 16 December 2021

Accepted: 7 January 2022

Published: 9 January 2022

Publisher's Note: MDPI stays neutral with regard to jurisdictional claims in published maps and institutional affiliations.

Copyright: (C) 2022 by the authors. Licensee MDPI, Basel, Switzerland. This article is an open access article distributed under the terms and conditions of the Creative Commons Attribution (CC BY) license (https:// creativecommons.org/licenses/by/ $4.0 /)$.
1 Gangnam Severance Hospital, Department of Surgery, Yonsei University College of Medicine, 211 Eonjuro, Gangnam-gu, Seoul 135-720, Korea; GSYHJ@yuhs.ac (H.J.Y.); surghsc@yuhs.ac (H.-S.C.)

2 Severance Biomedical Science Institute, Graduate school of Medical Science, BK21 Project, Yonsei University College of Medicine, Seoul 03722, Korea; louiskim100@yonsei.ac.kr (M.K.); sfang@yuhs.ac (S.F.)

3 Department of Surgery, Yonsei University College of Medicine, 50-1, Yonsei-ro, Seodaemun-gu, Seoul 120-752, Korea; 0101YONG@yuhs.ac

4 EONE-DIAGNOMICS Genome Center, New drug R\&D Center, 291 Harmony-ro, Yeonsu-gu, Incheon 22014, Korea; yonjung.kim@edgc.com

* Correspondence: docjang@yuhs.ac (H.-J.C.); ggiru95@yuhs.ac (K.C.P.); Tel.: +82-2-2019-3370 (H.-J.C.); +82-2-2228-2861 (K.C.P.); Fax: +82-2-3462-5994 (H.-J.C.); +82-2-362-8647 (K.C.P.)

$\dagger$ These authors contributed equally to this work.

\begin{abstract}
Thyroid cancer (TC) includes tumors of follicular cells; it ranges from well differentiated TC (WDTC) with generally favorable prognosis to clinically aggressive poorly differentiated TC (PDTC) and undifferentiated TC (UTC). Papillary thyroid cancer (PTC) is a WDTC and the most common type of thyroid cancer that comprises almost $70-80 \%$ of all TC. PTC can present as a solid, cystic, or uneven mass that originates from normal thyroid tissue. Prognosis of PTC is excellent, with an overall 10 -year survival rate $>90 \%$. However, more than $30 \%$ of patients with PTC advance to recurrence or metastasis despite anti-cancer therapy; consequently, systemic therapy is limited, which necessitates expansion of improved clinical approaches. We strived to elucidate genetic distinctions due to patientderived anti-cancer drug-sensitive or -resistant PTC, which can support in progress novel therapies. Patients with histologically proven PTC were evaluated. PTC cells were gained from drug-sensitive and -resistant patients and were compared using mRNA-Seq. We aimed to assess the in vitro and in vivo synergistic anti-cancer effects of a novel combination therapy in patient-derived refractory PTC. This combination therapy acts synergistically to promote tumor suppression compared with either agent alone. Therefore, genetically altered combination therapy might be a novel therapeutic approach for refractory PTC.
\end{abstract}

Keywords: patient-derived papillary thyroid cancer; paclitaxel; sorafenib; lenvatinib; drug-resistant papillary thyroid cancer; EMT; FGFR

\section{Introduction}

Thyroid cancer (TC) accounts for more than $90 \%$ of endocrine cancer, which is the most common endocrine malignancy, and its onset rate has risen over the past four decades [1]. TC is classified into four main types: follicular TC (FTC), medullary TC (MTC), papillary TC (PTC), and anaplastic TC (ATC) [2-4]. Furthermore, TC is commonly divided into differentiated and undifferentiated types according to its clinical manifestations $[5,6]$. Well differentiated TC (WDTC) generally has a favorable prognosis and is relatively easy to treat; however, poorly differentiated TC (PDTC) and undifferentiated TC (UTC) are unusual and aggressive, metastasize early, and have poor prognoses [7,8]. Molecular and biological mechanisms have demonstrated differing clinical behaviors between anti-cancer drugsensitive PTC and drug-resistant PTC. A number of studies have recommended that 
the range of mutations may be dissimilar between tumors in anti-cancer drug-sensitive patients and those in drug-resistant patients [9-14]. Though a few previous researchers have suggested molecular dissimilarities to describe the aggressive conduct of PTC in drugresistant patients, no investigation has yet offered an explicit account of the underlying mechanism. In view of the acquired drug resistance in refractory PTC, there is a requirement for useful clinical approaches [15-17]. Recent research trends have proven that progress of epithelial-mesenchymal transition (EMT) in refractory cancer cells not only results in metastasis but is also a critical causing factor in drug resistance via fibroblast growth factor receptor (FGFR) signaling $[18,19]$. While the affinity between EMT and drug resistance was established a short time ago, the system of refractory cancer remains ambiguous. EMT known as the physiological course wherein there is crumble of the cell-cell junctions of epithelial cells, which then change to a condition with properties of migratory cells $[20,21]$. Even though EMT is a crucial factor in resistance to ErbB aiming composites, deficient perception of the molecular process elementary course has restrained the advance of clinical approaches aimed at drug-resistance condition [22,23]. A few investigations have established that the FGFR signaling pathway plays a decisive role in EMT mediated poor prognosis and drug-resistance of refractory cancer [24-27] by its alteration of the aggressiveness or cancer stemness of refractory tumor cells.

In this study, we pointed to clarify the association between drug resistant and EMT on refractory PTC to clarify the unfortunate clinical consequences. In particular, we inspected the probable mechanism elementary to anti-cancer drug resistance to promote the expansion of new clinical approaches to address the issue of anti-cancer drug resistace.

\section{Results}

\subsection{Patient Disease Characteristics}

In total, 57 medical records of patients with advanced or metastatic PTC consecutively treated with paclitaxel $(n=5)$, lenvatinib $(n=36)$, or sorafenib $(n=16)$ at our center were analyzed. Patient disease characteristics and demographics by treatment agent are presented in (Figure 1A). The mean age of the patients was $53.2 \pm 13.6$ years, and $70.2 \%$ of patients were female. Distant metastases were observed in $84.2 \%$ of patients, and locally advanced PTC was identified in $15.8 \%$ of patients. The cases of distant metastatic lesions in the lungs were $40 \%, 88.9 \%$, and $87.5 \%$ in the paclitaxel, lenvatinib, and sorafenib groups, respectively, and in the bone $20 \%, 19.4 \%$, and $25.0 \%$, respectively. In the lenvatinib group, distant metastatic lesions of the brain were found in $8.3 \%$ of patients. All patients had received previous RAI, and the mean cumulative RAI was $442.0 \pm 241.3 \mathrm{mCi}$ among those treated with paclitaxel, $553.1 \pm 246.1 \mathrm{mCi}$ among those treated with Lenvatinib and $657.5 \pm 409.2 \mathrm{mCi}$ among those treated with sorafenib (Figure 1B). Furthermore, $47.4 \%$ of patients underwent external beam radiation therapy. Overall survival for 57 patients was $134.3 \pm 74.7$ months. The patient survival rate was $90.1 \%$ at 5 years and $86.1 \%$ at 10 years after detection of thyroid cancer (Figure 1C).

\subsection{Characteristics of Patient-Derived Drug Resistant PTC Cell Lines}

Various PTC cell lines were isolated from the specimens obtained from patients (Figure 2A); YUMC-S-P1 and YUMC-S-P2 (first and second isolated patient-derived drugsensitive PTC), and YUMC-R-P1, YUMC-R-P2, and YUMC-R-P3 (first, second, and third isolated patient-derived drug-resistant PTC) were isolated from patients with PTC who were cured at the Severance Hospital, Yonsei University College of Medicine, Seoul, Republic of Korea. YUMC-R-P1, YUMC-R-P2, and YUMC-R-P3 drug-resistant PTC were more aggressive than YUMC-S-P1 and YUMC-S-P2 drug-sensitive PTC, and metastasis or recurrence was reported in these patients (Figure 2A). Next-generation RNA sequencing to recognize a series of differentially indicated genes revealed that YUMC-R-P1, YUMCR-P2, and YUMC-R-P3 drug-resistant PTC cells showed induction of the FGFR signaling pathway and EMT markers (ZEB [zinc finger E-box-binding homeobox], SNAIL [zinc finger protein SNAI1], and TWIST [twist family bHLH transcription factor]) when compared with 
YUMC-S-P1 and YUMC-S-P2 drug-sensitive PTC cells (Figure 2B). In drug-resistant PTC, the most notably increased genes were fibroblast growth factor (FGF), FGFR, ZEB, SNAIL, and TWIST (Figure 2B). Cancer stem cells (CSCs), FGF, and EMT-related genes were highly expressed in drug-resistant PTC than in drug-sensitive PTC (Figure 2C). Especially, in KEGG pathway analysis, drug-resistant PTC showed upregulated cancer stemness signaling pathway (Wnt, Hedgehog, TGF/SMAD, PI3K/Akt, and PPAR signaling pathway) [28] than drug-sensitive PTC (Figure 2D-F).

A)

\begin{tabular}{|c|c|c|c|c|c|}
\hline Patient characteristics & $\begin{array}{l}\text { Paclitaxel } \\
N=5(\%)\end{array}$ & $\begin{array}{l}\text { Lenvatinib } \\
N=36(\%)\end{array}$ & $\begin{array}{l}\text { Sorafenib } \\
N=16(\%)\end{array}$ & $\begin{array}{c}\text { Total } \\
\mathrm{N}=57(\%)\end{array}$ & P-value \\
\hline Age, year \pm SD & $64.8 \pm 4.8$ & $50.3 \pm 14.2$ & $55.8 \pm 12.0$ & $53.2 \pm 13.6$ & 0.278 \\
\hline Sex, n & & & & & 0.805 \\
\hline Female & $3(60.0)$ & $25(69.4)$ & $12(75.0)$ & $40(70.2)$ & \\
\hline Metastasis, $\mathbf{n}$ & & & & & 0.018 \\
\hline Locally advanced & $3(60.0)$ & $4(11.1)$ & $2(12.5)$ & $9(15.8)$ & \\
\hline \multicolumn{6}{|l|}{ Distant metastatic lesion site (multiple) } \\
\hline Lung & $2(40.0)$ & $32(88.9)$ & $14(87.5)$ & $48(84.2)$ & 0.018 \\
\hline Bone & $1(20.0)$ & $7(19.4)$ & $4(25.0)$ & $12(21.1)$ & 0.901 \\
\hline Brain & 0 & $3(8.3)$ & 0 & $3(5.3)$ & 0.397 \\
\hline Other (kidney, mediastinum) & 0 & $4(11.1)$ & 0 & $4(7.0)$ & 0.285 \\
\hline $\begin{array}{l}\text { Cumulative radioiodine } \\
\text { activity, } \mathrm{mCi} \pm \mathrm{SD}\end{array}$ & $442.0 \pm 241.3$ & $553.1 \pm 246.1$ & $657.5 \pm 409.2$ & $572.6 \pm 301.1$ & 0.241 \\
\hline
\end{tabular}

B)

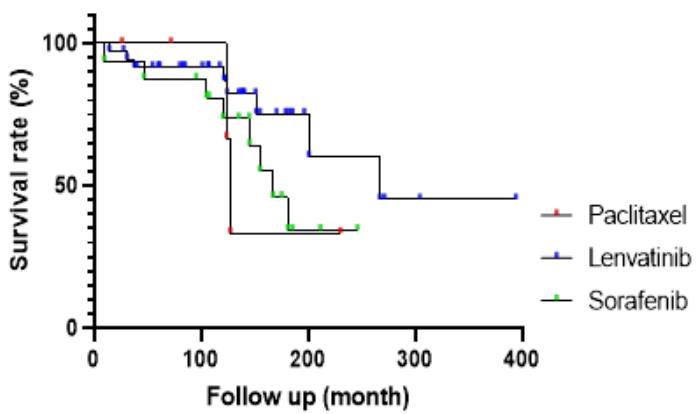

C)

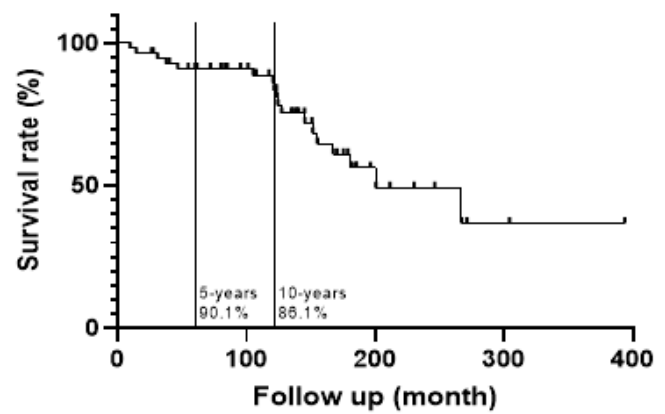

Figure 1. Information on patients with papillary thyroid cancer (PTC) after treatment of paclitaxel, lenvatinib and sorafenib: (A) patient characteristics and clinical features, (B) overall survival rate after treatment of paclitaxlel, Lenvatinib, and sorafenib, and (C) overall survival rate of patients with refractory PTC. 
A)

\begin{tabular}{|c|c|c|c|c|c|}
\hline & YUMC-S-P1 & YUMC-S-P2 & YUMC-R-P1 & YUMC-R-P2 & YUMC-R-P3 \\
\hline Age at Diagnosis & 31 & 42 & 52 & 57 & 34 \\
\hline Gender & Female & Male & Female & Male & Female \\
\hline Primary Disease Site & Thyroid & Thyroid & Thyroid & Thyroid & Thyroid \\
\hline Stage & T4aN1bM0 & T4aN1bM0 & T4aN1bM1 & T3N1bM1 & T4aN1bM1 \\
\hline Primary Pathology & $\begin{array}{l}\text { Papillary thyroid } \\
\text { cancer }\end{array}$ & $\begin{array}{l}\text { Papillary thyroid } \\
\text { cancer }\end{array}$ & $\begin{array}{l}\text { Papillary thyroid } \\
\text { cancer(Recurrence \& } \\
\text { Metastasis after } \\
\text { paclitaxel treatment) }\end{array}$ & $\begin{array}{l}\text { Papillary thyroid } \\
\text { cancer(Recurrence \& } \\
\text { Metastasis after } \\
\text { sorafenib treatment) }\end{array}$ & $\begin{array}{l}\text { Papillary thyroid } \\
\text { cancer(Recurrence \& } \\
\text { Metastasis after } \\
\text { sorafenib treatment) }\end{array}$ \\
\hline $\begin{array}{l}\text { Classification of speci } \\
\text { men used for culture }\end{array}$ & Fresh tumor & Fresh tumor & Fresh tumor & Fresh tumor & Fresh tumor \\
\hline Obtained from & $\begin{array}{l}\text { Severance Hospital, } \\
\text { Seoul, Korea }\end{array}$ & $\begin{array}{l}\text { Severance Hospital, } \\
\text { Seoul, Korea }\end{array}$ & $\begin{array}{l}\text { Severance Hospital, } \\
\text { Seoul, Korea }\end{array}$ & $\begin{array}{l}\text { Severance Hospital, } \\
\text { Seoul, Korea }\end{array}$ & $\begin{array}{l}\text { Severance Hospital, } \\
\text { Seoul, Korea }\end{array}$ \\
\hline
\end{tabular}

B)

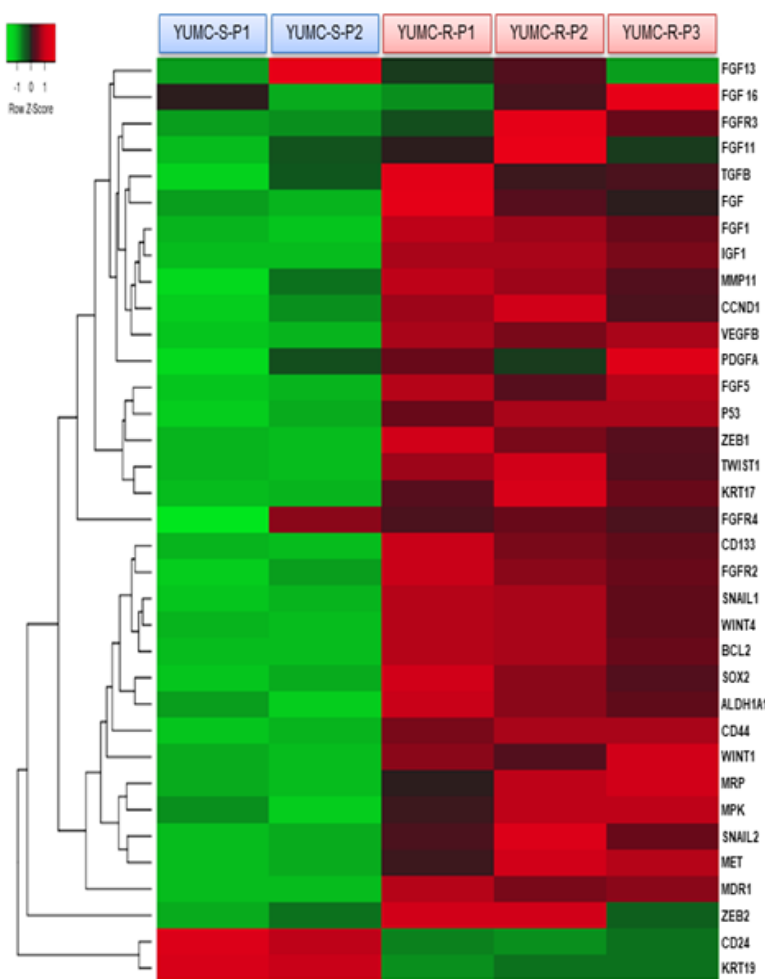

D)

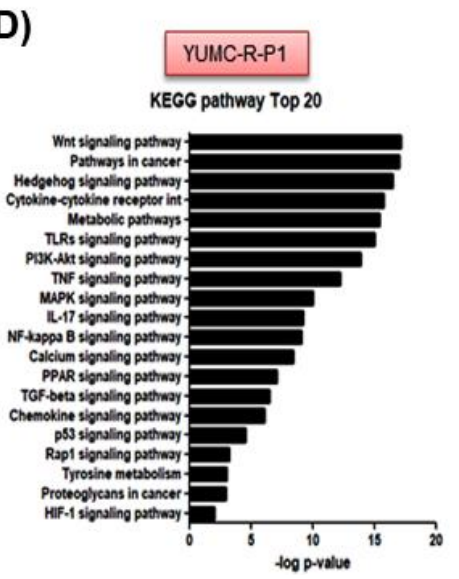

C)

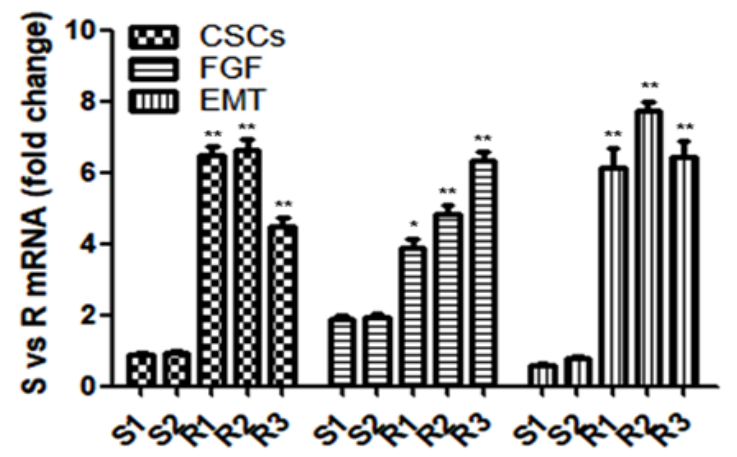

* CSCs: Cancer stemness related genes (CD44, CD133, ALDH). *FGF: FGF/FGFR related genes (FGF, FGFR).

${ }^{\star}$ EMT: EMT markers (transcriptional factor, Snail, ZEB, Twist).

Figure 2. Characteristics of all examined papillary thyroid cancer (PTC) cell lines. (A) Characteristics of patient-derived subtypes of PTC cell lines, (B) hierarchical clustering of annotated genes revealing 
distinct gene expression; gene expression profile differences between patient-derived drug-sensitive and drug-resistant PTC cells, and (C) gene expression level analysis based on mRNA seq for markers of cancer stem cells (CSC), fibroblast growth factor (FGF)/FGF receptor, and epithelial-mesenchymal transition (EMT) between patient-derived anti-cancer drug sensitive and resistant PTC cells. (D-F), bar plot showing 20 significantly enriched upregulated pathways in patient derived anti-cancer drug resistant PTC cells, YUMC-R-P1 (D), YUMC-R-P2 (E), and YUMC-R-P3 (F). ${ }^{*} p<0.05$ vs. anti-cancer drug-sensitive PTC cells, YUMC-S-P1, ${ }^{* *} p<0.01$ vs. anti-cancer drug-sensitive PTC cells, YUMC-S-P1.

Cumulatively, the findings regarding drug-resistant PTC can be of immense importance to the management and therapeutic trials of recurrence and metastasis in patients with aggressive PTC.

\subsection{Combination of Paclitaxel and Lenvatinib Was More Effective Than Either Agent Alone or a} Combination of Paclitaxel and Sorafenib

Based on the results of RNA-Seq-based transcriptome analysis (Figure 2), we hypothesized that the inhibition of FGFR could be a crucial therapeutic approach in paclitaxelor sorafenib-resistant cancer cells. Consequently, we selected lenvatinib, a multi-receptor tyrosine kinase inhibitor, and evaluated the synergistic anti-cancer effects of its combination with paclitaxel. However, as lenvatinib is included in the signaling pathway of sorafenib as well, a combination of the lenvatinib and sorafenib was excluded. For the assessment of anti-cancer efficacy of paclitaxel, sorafenib, and lenvatinib on patient-derived drug-sensitive and drug-resistant PTC cells, we investigated the proliferation of YUMCS-P1, YUMC-S-P2, YUMC-R-P1, YUMC-R-P2, and YUMC-R-P3 in the presence of drugs either in combination or alone. Cell viability was suppressed more efficiently with a combination of sorafenib or lenvatinib with paclitaxel than either agent alone and in a dose-dependent manner (Figure 3A,B). Notably, cell viability of drug-sensitive PTC was well-suppressed, regardless of which combination was used and even if the drugs were used alone (Figure 3A). However, cell viability of paclitaxel- or sorafenib-resistant PTC was not meaningfully impacted following treatment with paclitaxel or sorafenib, either separately or in combination (Figure 3B). However, the combination of paclitaxel and sorafenib seemed a little more effective than using either agent alone. While lenvatinib demonstrated more effective suppression than paclitaxel or sorafenib, the synergistic anti-cancer effect of the paclitaxel and lenvatinib combination showed noteworthy suppression of paclitaxel or sorafenib-resistant PTC (Figure 3B). This result proved that FGFR inhibition was critical in FGFR-EMT-mediated drug-resistant PTC. The combination therapy had a half-maximal inhibitory concentration $\left(\mathrm{IC}_{50}\right)$ than that with paclitaxel or sorafenib treatment alone or with lenvatinib in YUMC-R-P1, YUMC-R-P2, and YUMC-R-P3 cells (Figure 3C). These results demonstrated that cotreatment with paclitaxel and lenvatinib might be a new clinical approach worth exploring for targeting drug-resistant PTC.

\subsection{Paclitaxel and Lenvatinib Cotreatment Induced Nuclear Translocation-Mediated Apoptosis in} YUMC-R-P1, YUMC-R-P2, and YUMC-R-P3 Cells

Next, we tested the process of action of the synergistic anti-cancer effects of combined treatment with paclitaxel and lenvatinib in YUMC-R-P1, YUMC-R-P2, and YUMC-R-P3 cells. We used flow cytometry, immunoblot (whole-cell lysate or cellular fractionation), and immunofluorescence analyses with either paclitaxel, lenvatinib, and sorafenib alone or with combined paclitaxel and lenvatinib. The combination of paclitaxel and lenvatinib significantly induced the sub- $\mathrm{G}_{0} / \mathrm{G}_{1}$ population, thus resulting in induction of apoptosis (Figure 4A,C,E) in YUMC-R-P1, YUMC-R-P2, and YUMC-R-P3 cells compared with the use of either agent alone. Immunoblot analysis of the protein expression levels demonstrated that cotreatment with paclitaxel and lenvatinib resulted in a marked induction of C/EBP homologous protein (CHOP) levels, which are active apoptosis markers associated with ER (endoplasmic reticulum) stress, compared with that seen when using either agent alone or when combined paclitaxel and sorafenib was used (Figure 4B,D,F). In contrast, compared 
with using either agent alone, cotreatment resulted in a decrease in anti-apoptotic factor levels of Bcl-2, ZEB, Snail, p-ERK, MEK, and PKC, which are noted markers of the FGFR signaling pathway and EMT levels (Figure $4 \mathrm{~B}, \mathrm{D}, \mathrm{F}$ ). These results could indicate that the combination of paclitaxel and lenvatinib is most efficient in suppressing paclitaxel- or sorafenib-resistant PTC. Immunofluorescence analysis indicated that cytochrome $c$ was translocated to the nucleus, thus suggesting that cotreatment with paclitaxel and lenvatinib induced apoptosis more significantly than either paclitaxel, sorafenib, or lenvatinib alone via a cytochrome $c$-reliant pathway (Figure 4G-I). Immunoblot analysis after cellular fractionation validated that cytochrome $c$ was translocated to the nucleus after cotreatment or treatment with either agent alone (Figure 4J-L). In summary, these results demonstrate that the highest level of apoptosis was induced following cotreatment with paclitaxel and lenvatinib through ER stress- and cytochrome $c$-dependent pathways in patient-derived drug-resistant PTC cells.
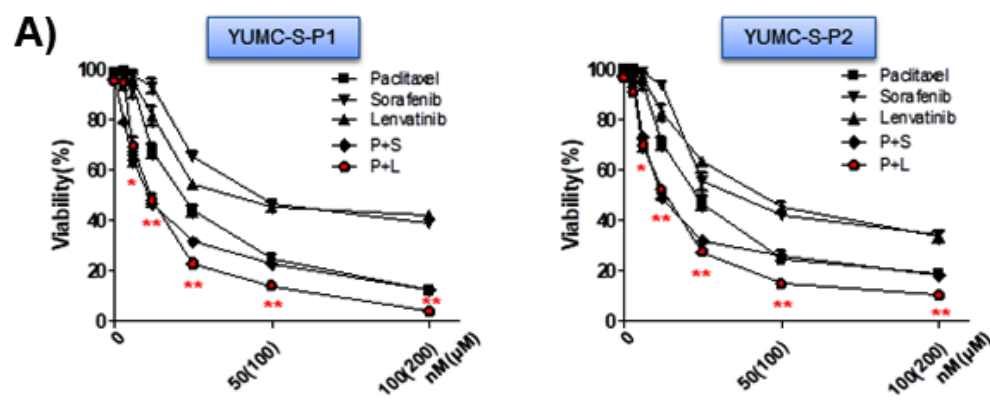

B)
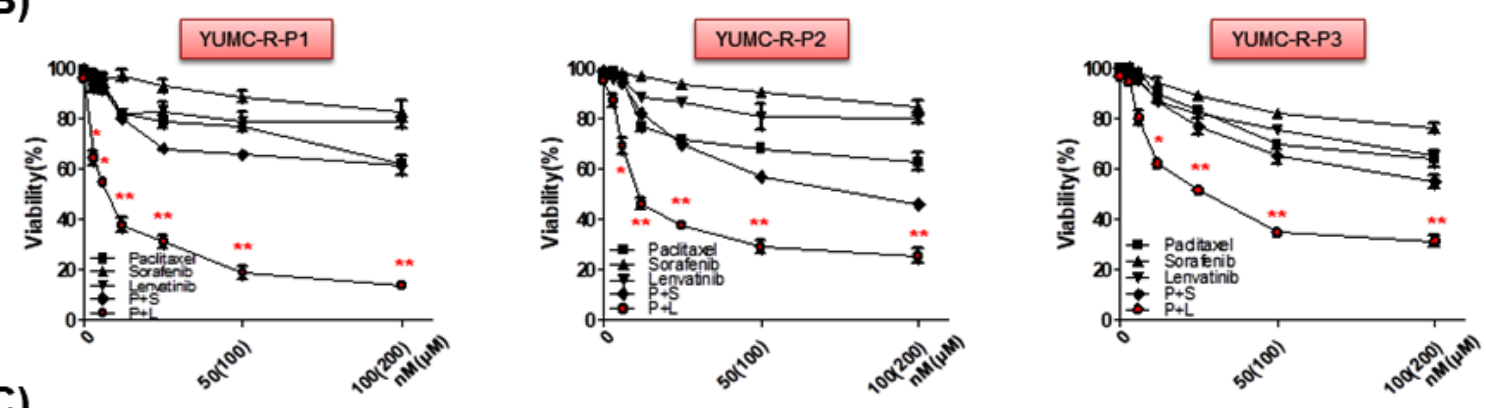

\begin{tabular}{|c|c|c|c|c|c|c|c|}
\hline Cell Line & Histopathology & Animal & & & Cell proliferati & ion $\left.\mathrm{IC}_{50}{ }^{*}\right)(\mu \mathrm{M})$ & \\
\hline & & & Paclitaxel(nM) & Sorafenib(uM) & Lenvatinib(uM) & $\mathbf{P}+\mathbf{S}$ & $\mathbf{P}+\mathbf{L}$ \\
\hline YUMC-R-P1 & Thyroid, Papillary & Human & - & - & - & - & $\left.9( \pm 0.2)+18( \pm 0.3)^{\star}\right)$ \\
\hline YUMC-R-P2 & Thyroid, Papillary & Human & - & - & - & $100( \pm 0.3)+200( \pm 0.1)$ & $\left.14( \pm 0.1)+27( \pm 0.3)^{*}\right)$ \\
\hline YUMC-R-P3 & Thyroid, Papillary & Human & - & - & - & - & $\left.27( \pm 0.3)+62( \pm 0.1)^{\star}\right)$ \\
\hline
\end{tabular}

Figure 3. Synergistic anti-cancer effect of paclitaxel and lenvatinib in anti-cancer drug-sensitive and drug-resistant papillary thyroid cancer (PTC) cells. Cell viability of anti-cancer drug-sensitive ((A), YUMC-S-P1 and YUMC-S-P2) and -resistant ((B), YUMC-R-P1, YUMC-R-P2, and YUMC-RP3) PTC cells with paclitxel, sorafenib, and levatinib combined or with each agent alone. Points indicate the mean percentage of the values observed in solvent-treated control. All experiments were performed at least thrice. Data represent mean \pm standard deviation. ${ }^{*} p<0.05$ and ${ }^{* *} p<0.01$ versus control. (C), Half-maximal inhibitory concentration $\left(\mathrm{IC}_{50}\right)$ values for the combination of sorafenib and lenvatinib in anti-cancer drug-sensitive and -resistant PTC cells. Each data point signifies the mean of three independent MTT assays, performed in triplicate. SEM, standard error of the mean; MTT, 3-(4,5-dimethylthiazol-2-yl)-2,5-diphenyltetrazolium bromide. The asterisk indicates the lowest half-maximal inhibitory concentration. 
A)

\begin{tabular}{|c|c|c|c|c|c|}
\hline & Status & Sub- $\mathbf{G}_{0} \mathbf{G}_{1}$ & $\mathbf{G}_{0} \mathbf{G}_{1}$ & $\mathrm{~S}$ & $\mathbf{G}_{2} / \mathbf{M}$ \\
\hline \multirow{5}{*}{$\begin{array}{l}\bar{\alpha} \\
\alpha \\
\alpha \\
\dot{d} \\
\sum \\
\sum\end{array}$} & Control & $3.4 \pm 0.03$ & $37.3 \pm 0.01$ & $33.1 \pm 0.04$ & $26.2 \pm 0.05$ \\
\hline & Paclitaxel & $17.6 \pm 0.02$ & $36.2 \pm 0.05$ & $29.6 \pm 0.02$ & $16.6 \pm 0.04$ \\
\hline & Sorafenib & $20.2 \pm 0.01$ & $39.8 \pm 0.04$ & $25.5 \pm 0.01$ & $14.5 \pm 0.02$ \\
\hline & Lenvatinib & $26.2 \pm 0.02$ & $38.4 \pm 0.01$ & $26.6 \pm 0.03$ & $8.8 \pm 0.02$ \\
\hline & $\mathrm{P}+\mathrm{S}$ & $33.4 \pm 0.01$ & $42.8 \pm 0.03$ & $14.0 \pm 0.03$ & $9.8 \pm 0.02$ \\
\hline & $\mathbf{P}+\mathbf{L}$ & $56.2 \pm 0.02$ & $31.4 \pm 0.01$ & $8.2 \pm 0.01$ & $4.2 \pm 0.03$ \\
\hline
\end{tabular}

C)

\begin{tabular}{|c|c|c|c|c|c|}
\hline & Status & Sub- $\mathbf{G}_{0} \mathbf{G}_{1}$ & $\mathbf{G}_{0} \mathbf{G}_{1}$ & $\mathrm{~s}$ & $\mathbf{G}_{2} / \mathbf{M}$ \\
\hline \multirow{5}{*}{ 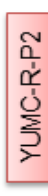 } & Control & $2.7 \pm 0.01$ & $27.5 \pm 0.03$ & $39.4 \pm 0.02$ & $30.4 \pm 0.01$ \\
\hline & Paclitaxel & $22.5 \pm 0.02$ & $40.7 \pm 0.02$ & $24.9 \pm 0.02$ & $11.9 \pm 0.03$ \\
\hline & Sorafenib & $8.4 \pm 0.02$ & $37.3 \pm 0.01$ & $39.4 \pm 0.04$ & $14.9 \pm 0.02$ \\
\hline & Lenvatinib & $19.7 \pm 0.04$ & $30.9 \pm 0.03$ & $32.6 \pm 0.01$ & $16.8 \pm 0.01$ \\
\hline & $\mathbf{P}+\mathbf{S}$ & $29.9 \pm 0.03$ & $41.9 \pm 0.01$ & $18.8 \pm 0.02$ & $9.4 \pm 0.01$ \\
\hline & $\mathrm{P}+\mathrm{L}$ & $51.9 \pm 0.02$ & $33.2 \pm 0.03$ & $13.2 \pm 0.04$ & $1.7 \pm 0.01$ \\
\hline
\end{tabular}

E)

\begin{tabular}{|c|c|c|c|c|c|}
\hline & Status & Sub- $\mathbf{G}_{0} \mathbf{G}_{1}$ & $\mathbf{G}_{0} \mathbf{G}_{1}$ & $\mathbf{s}$ & $\mathbf{G}_{2} / \mathbf{M}$ \\
\hline \multirow{5}{*}{$\begin{array}{l}m \\
\frac{1}{\alpha} \\
\frac{1}{j} \\
\frac{0}{3} \\
\frac{1}{2}\end{array}$} & Control & $4.4 \pm 0.01$ & $30.1 \pm 0.02$ & $38.9 \pm 0.01$ & $26.6 \pm 0.02$ \\
\hline & Paclitaxel & $18.7 \pm 0.01$ & $38.4 \pm 0.03$ & $31.7 \pm 0.03$ & $11.2 \pm 0.02$ \\
\hline & Sorafenib & $11.3 \pm 0.01$ & $36.4 \pm 0.03$ & $31.6 \pm 0.02$ & $20.7 \pm 0.03$ \\
\hline & Lenvatinib & $18.4 \pm 0.01$ & $31.8 \pm 0.02$ & $33.2 \pm 0.02$ & $16.6 \pm 0.01$ \\
\hline & $\mathbf{P}+\mathbf{S}$ & $29.8 \pm 0.02$ & $41.8 \pm 0.01$ & $16.7 \pm 0.02$ & $11.7 \pm 0.01$ \\
\hline & $\mathbf{P}+\mathbf{L}$ & $48.7 \pm 0.01$ & $35.5 \pm 0.01$ & $10.5 \pm 0.03$ & $5.3 \pm 0.03$ \\
\hline
\end{tabular}

B)

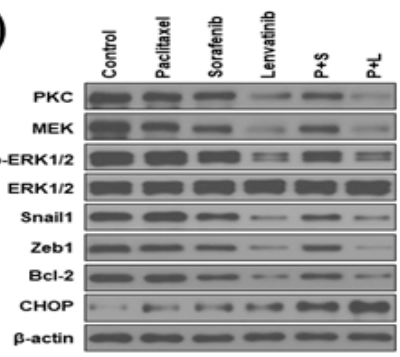

D)

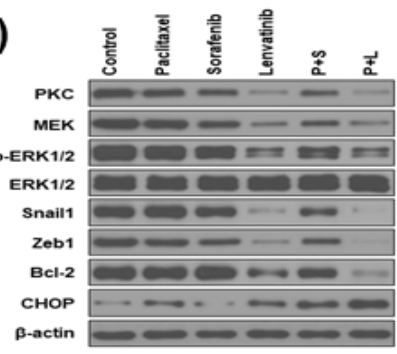

F)

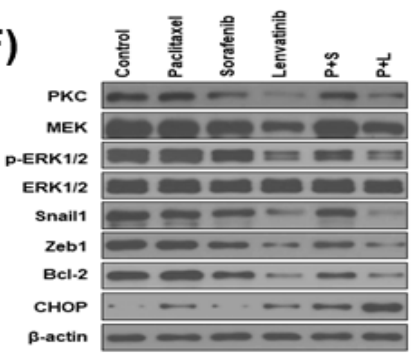

G)

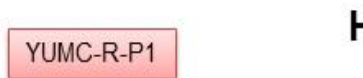

H)

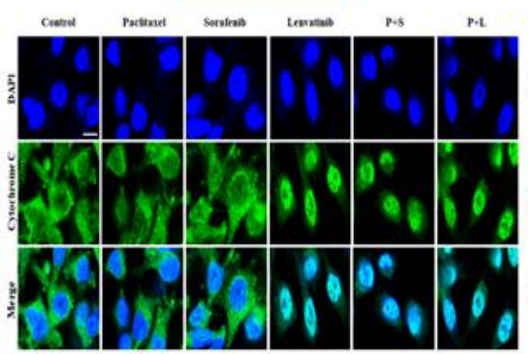

$\begin{array}{lll}\text { H) } & \text { YUMC-R-P2 }\end{array}$

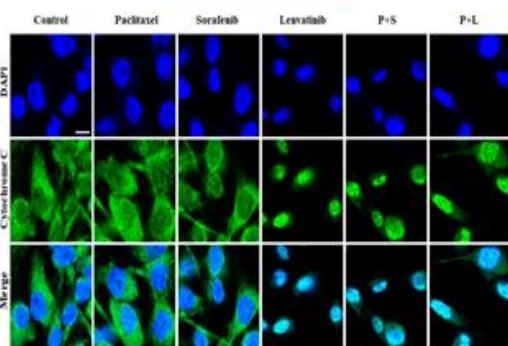

I) YUMC-R-P3

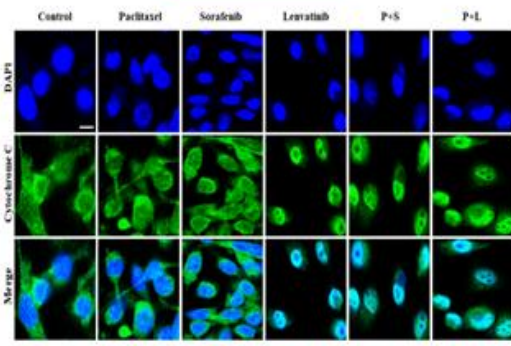

J)

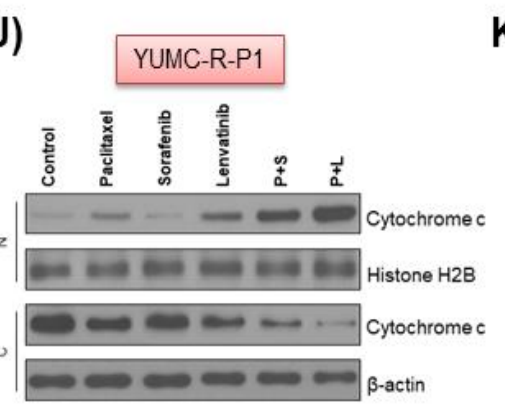

K)

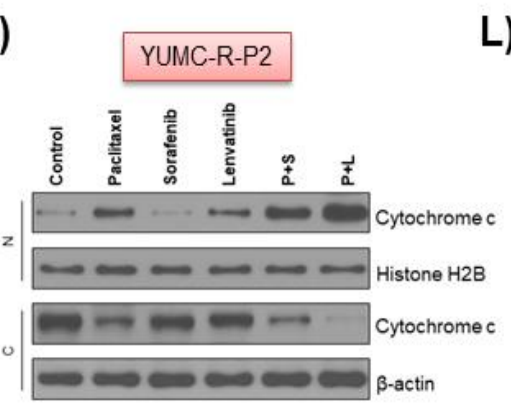

L)

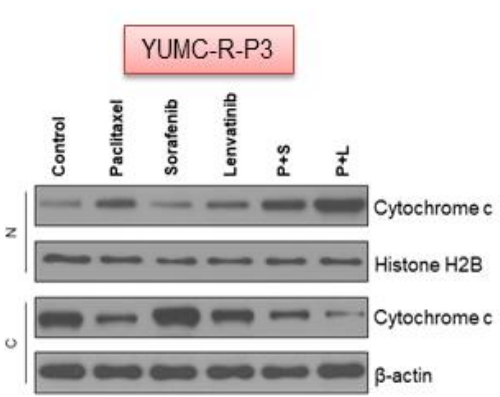

Figure 4. Apoptosis analysis by quantitation of DNA content with propidium iodide, immunoblot, and immunofluorescence analyses. Flow cytometry $(\mathbf{A}, \mathbf{C}, \mathbf{E})$ and immunoblot analyses $(\mathbf{B}, \mathbf{D}, \mathbf{F})$ of patientderived anti-cancer drug-resistant papillary thyroid cancer (PTC) cells, YUMC-R-P1, YUMC-R-P2, and 
YUMC-R-P3. (A,C,E), Cells were exposed to the indicated inhibitors, harvested, and stained with propidium iodide before analysis by flow cytometry and further assessment using FlowJo version 8. (B,D,F), Immunoblot analysis of the markers of endoplasmic reticulum stress, EMT, and anti-apoptosis in YUMC-R-P1, YUMC-R-P2, and YUMC-R-P3. (G,H,I), Immunofluorescence examined at $400 \times$ magnification; scale bar: $20 \mu \mathrm{m}$ and $(\mathbf{J}, \mathbf{K}, \mathbf{L})$ subcellular fractionation analysis. $(\mathbf{J}, \mathbf{K}, \mathbf{L})$, Cytochrome $c$ was the most translocated, and it accumulated in the nucleus in the paclitxel and lenvatinib cotreatment group. Combination of paclitaxel and lenvatinib resulted in the most induced nuclear translocation of cytochrome $c$-mediated apoptosis in anti-cancer drug-resistant PTC cell lines, YUMC-R-P1, YUMC-R-P2, and YUMC-R-P3.

\subsection{Paclitaxel and Lenvatinib Cotreatment Remarkably Suppressed Tumor Growth in a Mouse} Xenograft Model with Patient-Derived Drug-Resistant PTC Cell Lines

To determine the synergistic in vivo anti-cancer efficacy of the cotreatment with paclitaxel and lenvatinib, we established a mouse xenograft model with YUMC-R-P1, YUMC-RP2, and YUMC-R-P3 patient-derived PTC cell lines (Figure 5). We found that paclitaxel, sorafenib, and lenvatinib alone could not significantly inhibit tumor growth; however, compared with using these agents alone, cotreatment with paclitaxel and lenvatinib induced drastic tumor shrinkage (Figure 5A,D,G). Of note, cotreatment with paclitaxel and sorafenib seemed to induce tumor shrinkage compared with that seen using paclitaxel, sorafenib, or lenvatinib treatment alone. However, tumor growth is steadily increasing (Figure 5A,D,G). Mice in the paclitaxel and lenvatinib cotreatment group had a markedly smaller dissected tumor weight than mice treated with paclitaxel, sorafenib, or lenvatinib alone or in combination with paclitaxel and sorafenib (Figure 5B,E,H). There was no evidence of systemic toxicity and mortality in any group. The body weight of mice did not remarkably differ between the groups (Figure 5C,F,I). Anti-apoptotic activity is critical for the estimation of tumorigenesis, and Bcl-2 serves as a marker of anti-apoptotic activity; therefore, we confirmed its presence by performing immunohistochemistry analysis on YUMC-R-P1, YUMC-R-P2, and YUMC-R-P3 cell xenograft tumors. We found that the mice in the paclitaxel and lenvatinib cotreatment group demonstrated the maximum decrease in Bcl-2 expression among all groups (Figure 6A-C).

Cumulatively, the combination of paclitaxel and lenvatinib demonstrated potent anticancer effects in a patient-derived EMT-FGFR signaling pathway-mediated drug-resistant PTC cell xenograft model. 

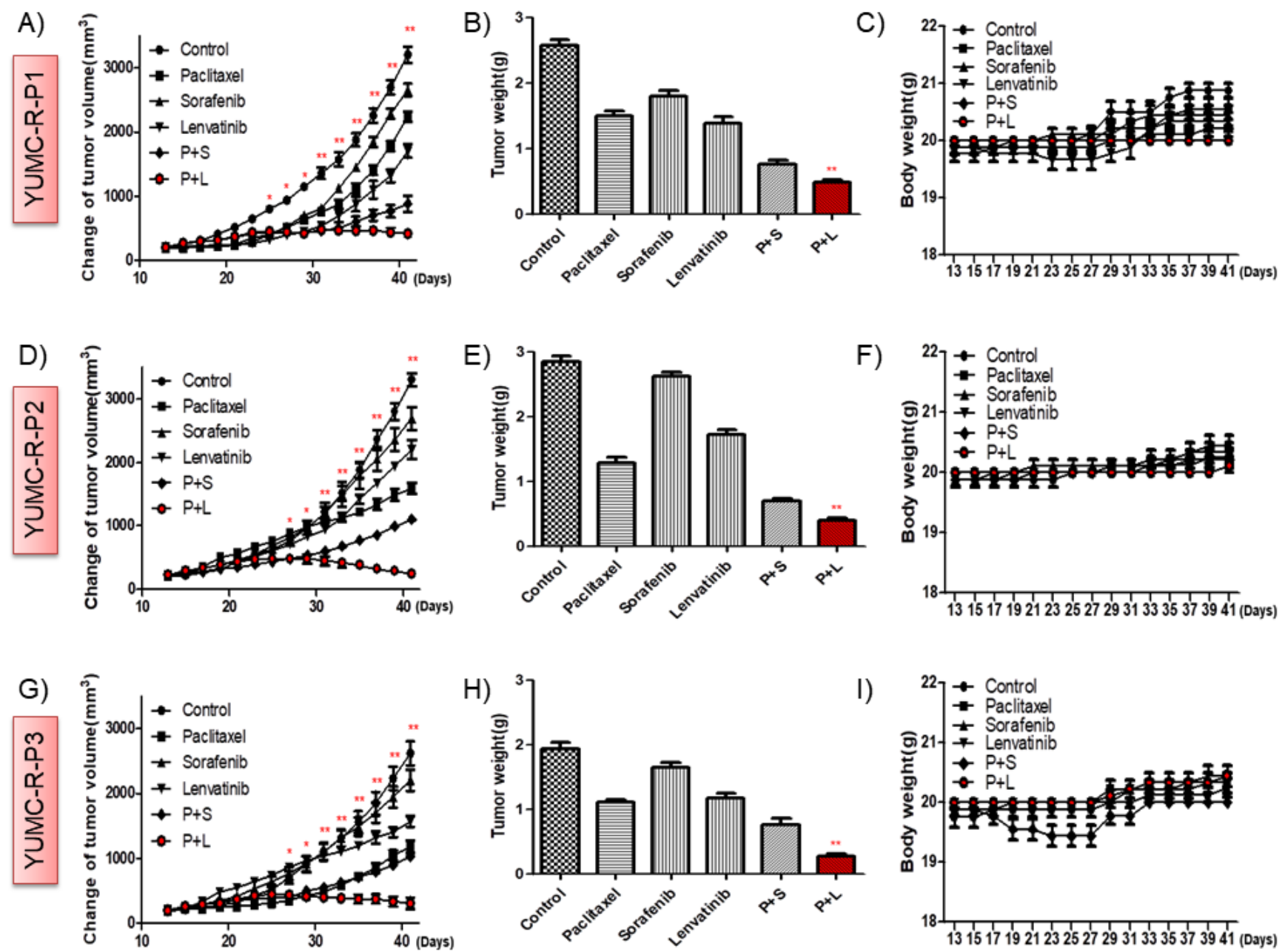

Figure 5. Combination of paclitaxel and lenvatinib produced the highest tumor shrinkage in patientderived anti-cancer drug (paclitaxel or sorafenib)-resistant papillary thyroid cancer (PTC) cells, YUMC-R-P1, YUMC-R-P2, and YUMC-R-P3 xenografts in vivo. (A,D,G), Change in tumor volume, $(\mathbf{B}, \mathbf{E}, \mathbf{H})$, the dissected tumor weight, and (C,F,I), change in whole body weight. Paclitxel, sorafenib, and lenvatinib alone had no significant effect on the mouse body weight. ${ }^{*} p<0.05$ and ${ }^{* *} p<0.01$, compared with control. 


\section{A)}
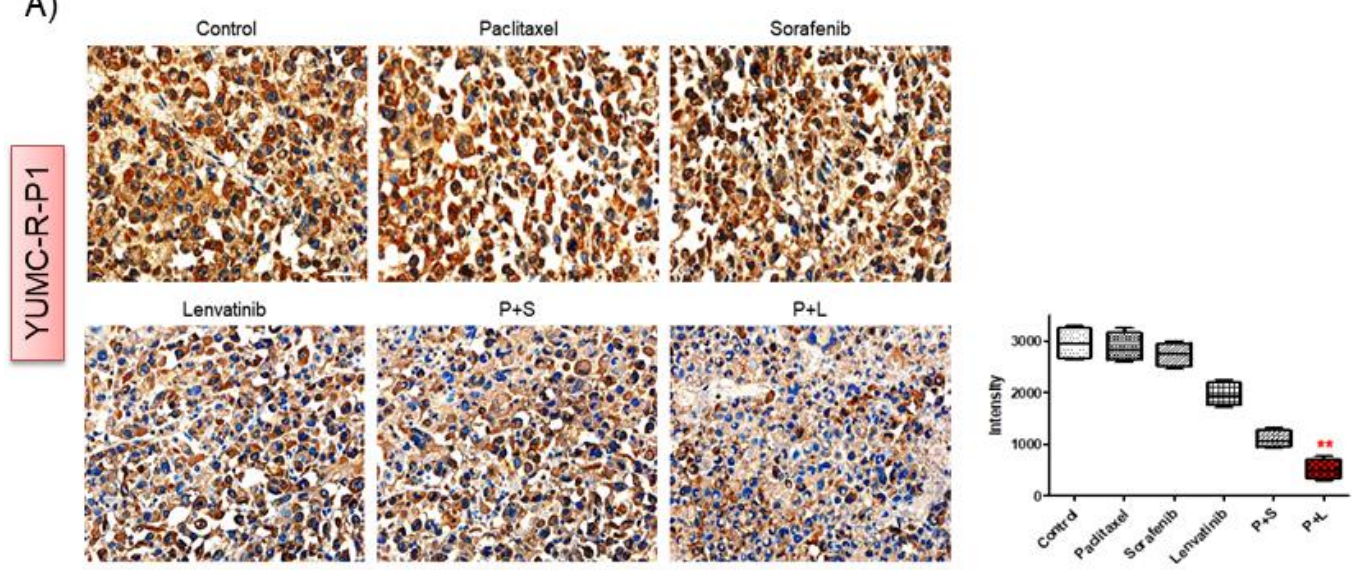

B)
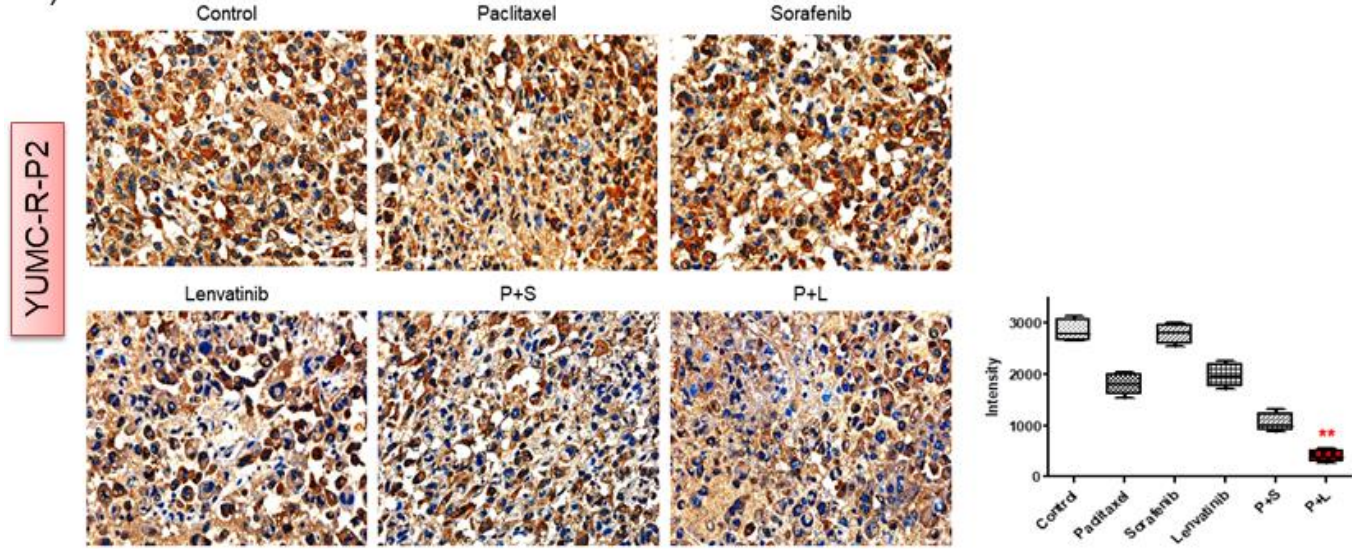

C)
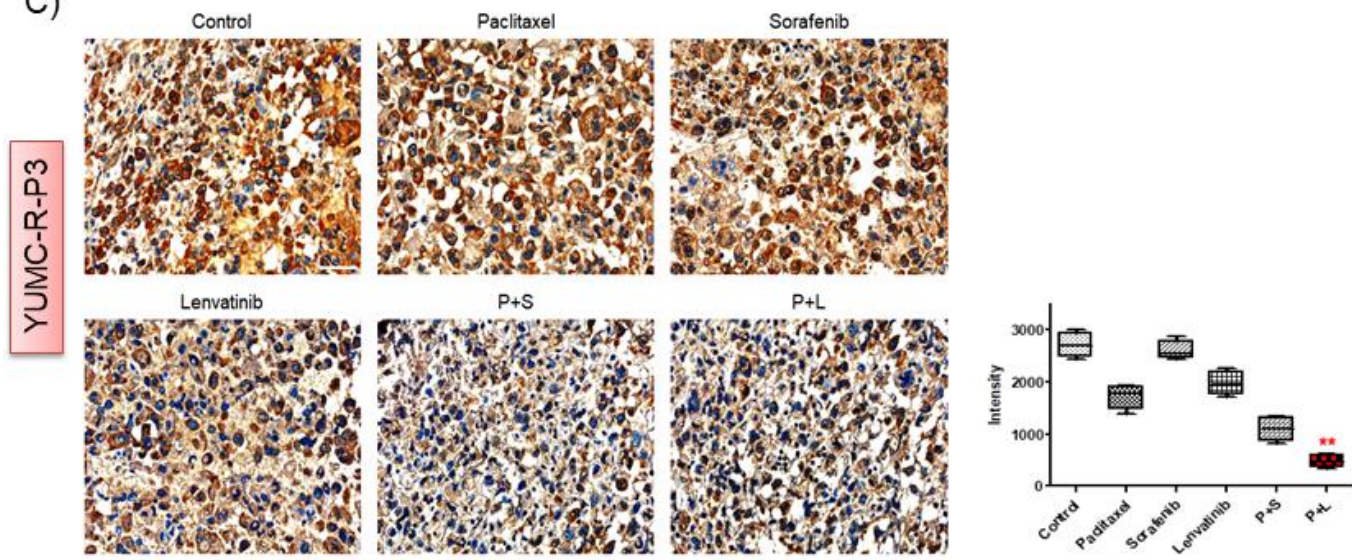

Figure 6. Immunohistochemical analysis of Bcl-2 proteins in tumor tissues following the indicated treatments. (A), YUMC-R-P1, (B), YUMC-R-P2, and (C), YUMC-R-P3 cells examined at $400 \times$ magnification; scale bar: $80 \mu \mathrm{m}$. Each assay was performed in triplicate, and the representative images are presented. ${ }^{* *} p<0.01$ versus control. MetaMorph 4.6 image analysis software was used to quantify the immunostained target proteins.

\section{Discussion}

The mortality rate of TC is the highest among common endocrine-mediated malignancies [29], and TC incidence is steadily increasing worldwide, including in the Republic of Korea [29-32]. TC is projected to become the fourth leading cause of cancer worldwide [31]. Over the past two decades, the universal age-standardized incidence of TC has increased by approximately $25 \%[31,33,34]$. This global increase has been attributed to causes such as increased risk factors, early detection of cancer, increased environmental risk factors, 
and iodine levels [31]. PTC is known as a general endocrine cancer with excellent prognosis $[35,36]$. However, unfortunately, several studies have demonstrated that recurrent or metastatic PTC is refractory to most medical treatments [8,37-40]. Such refractory PTC is usually slothful; however, following anaplasia of the lesion, it becomes undifferentiated cancer that then expands quickly, leading to poor prognosis $[41,42]$. During TC tumorigenesis, various oncogenic mechanisms as well as cytogenetic events have been reported [43-46]. In particular, according to well-known previous studies, the ret proto-oncogene rearrangement is a particular genetic alteration observed in PTC but never in UTC [43,47]. The mechanism of aggressiveness in refractory PTC has not been clarified so far. In our next research, we will strive to elucidate the cause for the aggressiveness in refractory PTC. For profiling of the genetic alterations, mRNA-seq analysis was performed to compare patient-derived anti-cancer drug-sensitive PTC and drug-resistant PTC. Countless genes were suggested between drug-sensitive and drug-resistant PTC, revealing that EMT was the principal factor in cancer stemness and aggressiveness [48]. EMT-related genes were more highly induced in drug-resistant PTC when compared with that in drug-sensitive PTC. There has been much debate over the reasonable therapy for patients with drug-sensitive and drug-resistant PTC. We especially concentrated on inspecting cancer cells separated from PTC patients who indicated drug resistance. Established studies have indicated that therapeutic failure in refractory cancer is due to drug resistance [49-51]. EMT of cancer is identified as metastasis, invasion, malignant progression, and drug resistance [52,53]. CSCs, discovered in cancer, were hypothesized to be behind the poor prognosis. Furthermore, their stem cell-like oddities [54,55], such as the capability of self-renewal, led them to induce recurrence, metastasis, and therapeutic resistance in tumors [56]. Previous studies have verified a connection among drug resistant, EMT, and CSCs [57-60]. Particularly, CSCs that demonstrated EMT were regarded to be critical for metastasis and drug resistance, as has been reported in innumerable human drug-refractory cancers [57,58,61]. A few studies have also demonstrated the association between drug resistance and EMT in CSCs $[57,58,62]$. Of note, in the current study, refractory PTC had properties alike to CSCs in terms of EMT-mediated stemness.

In the current research, the result of the in vivo model proved that sorafenib, lenvatinib, or paclitaxel alone could not conspicuously suppress drug-resistant PTC when compared with drug-sensitive PTC. However, sorafenib or lenvatinib with paclitaxel markedly suppressed the tumors in drug-resistant PTC. Additionally, selected drug combinations based on genetic alterations were demonstrated to be the most efficient at tumor suppression. Our findings highlight that paclitaxel, sorafenib, or lenvatinib-resistant patient-derived PTC cells could be frustrated by synergistic effects of combined sorafenib or lenvatinib with paclitaxel via the inhibition of Bcl-2 and EMT-mediated FGFR signaling pathway. It is an established fact that the proto-oncogene and anti-apoptotic factor Bcl-2 plays a major role in the regulation of apoptosis $[63,64]$. These could prove that Bcl-2 is associated with EMT, a crucial mechanism in the development of drug resistance in PTC [65]. Furthermore, release of cytochrome $c$ from the mitochondria is a crucial event for apoptosis [66]. Particularly, the released cytochrome $c$ induces the caspase-mediated apoptotic signaling pathway [67]. We proved that cytochrome $c$, released from the mitochondria, induced apoptosis and gradually amassed in the nucleus, as proven by both immunofluorescence and cellular fractionation after treatment with sorafenib or lenvatinib with paclitaxel. These findings might be valuable in designing future rational clinical approaches for patients with refractory PTC. Our future and prospective treatment strategies are to find new mechanisms or hit-to-lead for refractory cancer based on mRNAseq of patient derived cancer cells. In particular, we will focus on 'target validation and selection', 'hit and lead generation', 'lead optimization to identify a clinical drug candidate', and 'biomarker-led clinical trials'. Other investigations include enlargement of the envelope of druggability for less manageable targets, surmounting and understanding drug resistance, and designing intelligent and available drug combinations. Of course, further investigations are needed to assess the 
current clinical approach. Furthermore, additional studies are needed due to the fact that only a few patient outcomes were assessed in the current study.

Nevertheless, it is worth noting that these discoveries recommend that therapeutic approaches were founded on genetics, for instance, those involving downregulation of the EMT-mediated FGFR signaling pathway, are possible novel clinical approaches for patients with refractory cancer with drug-resistant properties.

\section{Materials and Methods}

\subsection{Study Design and Ethical Considerations}

This study was a retroactive, single center examination of patients diagnosed with PTC (January 2003-December 2019), as detailed in our previous study [68]. All courses entailing patients were achieved in proportion to the institutional ethical standards, whole applicable national/local regulations, and guidelines of the 1964 Helsinki Declaration and its later amendments. The study proceedures were authorized by the Institutional Review Board (IRB) of Severance Hospital, Yonsei University College of Medicine (IRB protocol: 3-2019-0281). Cancer cells were obtained from fresh tissue of patients at the Severance Hospital, Yonsei University College of Medicine, Seoul, Korea.

\subsection{Patients}

\subsubsection{Patient 1}

YUMC-R-P1 was a 52-year-old woman with PTC. This patient had multiple tumors and extensive extrathyroidal extension. This woman experienced a bilateral total thyroidectomy with main compartment neck resection. One year after surgery, metastasis to the mediastinum and right lateral cervical lymph nodes was confirmed, and she underwent a mediastinal dissection through partial sternotomy and right modified radical neck dissection. The specimens for culture were gained after the last surgery. After surgery, the pathology state revealed the existence of metastatic papillary thyroid carcinoma.

\subsubsection{Patient 2}

YUMC-R-P2 was a 57-year-old man with poorly differentiated thyroid carcinoma. After a bilateral total thyroidectomy with main compartment neck resection, this man experienced left radical nephrectomy and right lung wedge resection for kidney and lung metastasis. Afterward, he underwent a right modified radical neck dissection, left lateral selective lymph node dissection, and 2 regional lymph node dissections. The specimens for culture were gained after the last surgery. After regional lymph node dissection (left level III), the pathology state revealed the existence of metastatic poorly differentiated thyroid carcinoma.

\subsubsection{Patient 3}

YUMC-R-P3 was a 34-year-old woman with PTC. She experienced a bilateral total thyroidectomy with main compartment neck resection and right modified radical neck dissection. One year after surgery, metastasis to the mediastinum was confirmed, and she underwent mediastinal dissection through transcervical approach. Then, metastasis to the upper mediastinum was confirmed, and mediastinal dissection was additionally performed. The specimens for culture were obtained after the second surgery. After surgery, the pathology state revealed the existence of metastatic papillary thyroid carcinoma.

\subsection{Specimens of Patients}

Fresh tumors were gained from patients with biochemical and histologically established PTC who were attended at the Severance Hospital, Yonsei University College of Medicine, Seoul, Korea. Fresh tumors were acquired via surgical resection of PTC metastatic and primary sites. 


\subsection{Tumor Cell Isolation and Primary Culture}

After resection, tumors were placed in phosphate-buffered saline (PBS) with antibiotics and antifungal and moved to the laboratory. Further details on the protocol can be found in our previous article [68].

\section{5. $m R N A$-Seq Data}

We preprocessed the raw reads from the sequencer to remove low quality and adapter sequence before analysis and aligned the processed reads to the Homo sapiens (GRCh37) using HISAT v2.1.0 (KIM et al., 2015) as detailed in previous research [69].

\subsection{Statistical Aanalysis of Gene Expression Level}

The relative abundances of gene were measured in Read Count using StringTie. Further details on the protocol can be found in 'www.frontiersin.org' (accessed on 15 December 2021).

\subsection{Hierarchical Clustering}

Hierarchical clustering analysis was carried out with complete linkage and Euclidean distance as a measure of similarity to indicate the expression patterns of differentially expressed transcripts which are satisfied with $\mid$ fold change $\mid \geq 2$ and independent $t$-test raw $p<0.05$. All data analysis and visualization of differentially expressed genes was conducted using R 3.5.1 (www.r-project.org, accessed on 15 December 2021).

\subsection{Cell Culture}

The PTC cell lines YUMC-R-P1, -P2, and -P3 were obtained by tumor cell isolation from the patients and cultured in RPMI-1640 medium with 15\% fetal bovine serum (FBS; authenticated by short tandem repeat profiling/karyotyping/isoenzyme analysis).

\subsection{Cell Viability Assay}

Cell viability was measured using the MTT (3-(4,5-Dimethylthiazol-2-yl)-2, 5 -Diphenyltetrazolium Bromide) assay, cells were seeded in 96 -well plates at $7 \times 10^{3}$ cells per well and incubated overnight to achieve $80 \%$ confluency. Further details on the protocol can be found in our previous article [68]. Data were indicated as a percentage of the signal observed in vehicle-treated cells and are shown as the means \pm SEM of triplicate experiments.

\subsection{Cell CycleAnalysis Using Flow Cytometry}

Cells were treated paclitaxel, sorafenib, and lenvatinib either alone or in combination (except a combination of sorafenib and lenvatinib) in RPMI-1640 medium containing $15 \%$ FBS for $40 \mathrm{~h}$. Further details on the protocol can be found in our previous article [68]. This experiment was repeated in triplicate and the results were averaged.

\subsection{Immunofluorescence Analysis and Confocal Imaging}

The expression of cytochrome $c$ was analyzed by immunofluorescence staining. Cells grown on glass-bottomed dishes (MatTek, Ashland, MA, USA) were fixed with $4 \%$ formaldehyde solution (R\&D Systems, Abingdon, UK) for $10 \mathrm{~min}$ and permeabilized with $0.5 \%$ TritonX-100 in phosphate-buffered saline (PBS) for $10 \mathrm{~min}$. Slides were air-dried, washed with PBS, and incubated with anti-cytochrome $c$ (1:25; Abcam, Cambridge, UK) in 3\% bovine serum albumin in PBS. Further details on the protocol can be found in our previous article [68]. Images were observed under a confocal microscope (LSM Meta 700; Zeiss, Oberkochen, Germany) and were analyzed using Zeiss LSM Image Browser, version 4.2.0121.

\subsection{Cellular Fractionation}

Cellular fractions were contrived with the NEPER Nuclear and Cytoplasmic Extraction kit (Thermo Scientific, 78833, Waltham, MA, USA) in conformity with the manufacturer's dicates. 


\subsection{Immunoblot Analysis}

After transfer process, the primary antibodies against CHOP purchased from Cell Signaling Technology; Danvers, MA, USA, Bcl-2, cytochrome $c$, Snail1, Zeb1, and histone H2B purchased from Abcam; and PKC, MEK, p-ERK, ERK, and $\beta$-actin purchased from Santa Cruz Biotechnology, Santa Cruz, CA, USA were maintained overnight at $4{ }^{\circ} \mathrm{C}$. As detailed in previous research [70].

\subsection{Human PTC Cell Xenograft}

Whole experiments were confirmed by the Animal Experiment Committee of Yonsei University. YUMC-R-P1, -P2, and -P3 patient-derived PTC cells $\left(4.4 \times 10^{6}\right.$ cells $/$ mouse $)$ were cultured in vitro, then injected subcutaneously into the upper left flank region of female NOD/Shi-scid, IL-2R $\gamma$ KOJic (NOG) mice. After 15 days, tumor cell planting mice were arranged arbitrarily ( $n=10$ per group). They were administered with $25 \mathrm{mg} / \mathrm{kg}$ Paclitaxel (i.p.), $80 \mathrm{mg} / \mathrm{kg}$ sorafenib (p.o.), and $10 \mathrm{mg} / \mathrm{kg}$ lenvatinib (p.o.) either alone or in combination. Tumor volume was quantified every two days by calipers. Tumor volume was gauged by formula: $\mathrm{L} \times \mathrm{S} 2 / 2$ (L, longest diameter; $\mathrm{S}$, shortest diameter). Mice were kept under specific pathogen-free conditions. Whole experiments were established by the Animal Experiment Committee of Yonsei University.

\subsection{Immunohistochemistry}

Primary monoclonal antibodies against Bcl-2 (Abcam) were diluted with PBS (1:100) overnight at $4{ }^{\circ} \mathrm{C}$. All tissue sections were counterstained with hematoxylin, dehydrated, and mounted.

\subsection{Image Analysis}

The MetaMorph 4.6 software (Molecular Devices, San Jose, CA, USA) was used for computerized quantification of immunostained target proteins.

\subsection{Statistical Analysis}

For the assay of patient report, unequivocal fluctuations were expressed as frequency and proportion, whereas summary statistics (median, range) were used to report continuous data. Survival curves were generated using the Kaplan-Meier method based on the log-rank test. As this was a retrospective analysis, no formal statistical comparisons were performed. Statistical analyses were performed using GraphPad Prism 6.0 software (GraphPad Software, La Jolla, CA, USA), Microsoft Excel (Microsoft Corp, Redmond, WA, USA), and $\mathrm{R}$ version 2.17. One-way ANOVA was performed for the multi group analysis, and a two-tailed Student $t$-test was performed for the two-group analysis. Immunohistochemistry results were subjected to one-way analysis of variance, followed by Bonferroni post hoc test. Values were expressed as the mean \pm standard error of mean. $p$ values $<0.05$ were considered statistically significant.

\section{Conclusions}

The synergistic anti-cancer activity of paclitaxel and lenvatinib was more effective than that of either agent alone in patient-derived drug-resistant PTC. These findings might be useful in designing future clinical studies and aid in the development of effective therapies for patients with advanced or metastatic PTC.

Author Contributions: H.-J.C. and K.C.P. performed most of the in vitro and in vivo experiments. H.J.Y., Y.K., and M.K. drafted the manuscript. M.K. and S.Y.K. performed the statistical analysis. S.F. and H.-S.C. were involved in the study design and drafting of the manuscript. K.C.P. and H.-J.C. were involved in the study design, experiments, manuscript drafting, and revision of the manuscript. All authors have read and agreed to the published version of the manuscript.

Funding: This study was supported by the Basic Science Research Program through the National Research Foundation of Korea (NRF) funded by the Ministry of Education (NRF-2017R1D1A1B03029716), 
a grant of the Korea Health Technology R\&D Project through the Korea Health Industry Development Institute (KHIDI), funded by the Ministry of Health \& Welfare, Republic of Korea (grant number: HI18C1188), and EONE-DIAGNOMICS Co., Ltd. (grant number: 2021-31-1010). This study was supported by research grants from Hanmi Pharmaceutical Co., Ltd.

Institutional Review Board Statement: The study was conducted according to the guidelines of the Declaration of Helsinki and approved by the Institutional Review Board of Severance Hospital, Yonsei University College of Medicine (IRB protocol: 3-2019-0281; 21 April 2019).

Informed Consent Statement: Informed consent was obtained from all subjects involved in the study.

Data Availability Statement: The data presented in this study are available on reasonable request from the corresponding author.

Acknowledgments: We are grateful for the support provided by Jung Min Kim, Severance Biomedical Science Institute, Yonsei University College of Medicine.

Conflicts of Interest: The authors declare no conflict of interest.

\section{References}

1. Nikiforov, Y.E. Thyroid carcinoma: Molecular pathways and therapeutic targets. Mod. Pathol. Off. J. United States Can. Acad. Pathol. 2008, 21, S37-S43. [CrossRef] [PubMed]

2. Nguyen, Q.T.; Lee, E.J.; Huang, M.G.; Park, Y.I.; Khullar, A.; Plodkowski, R.A. Diagnosis and treatment of patients with thyroid cancer. Am. Health Drug Benefits 2015, 8, 30-40.

3. Fahiminiya, S.; de Kock, L.; Foulkes, W.D. Biologic and clinical perspectives on thyroid cancer. N. Engl. J. Med. 2016, 375, 2306-2307.

4. $\quad$ Owonikoko, T.K.; Chowdry, R.P.; Chen, Z.; Kim, S.; Saba, N.F.; Shin, D.M.; Khuri, F.R. Clinical efficacy of targeted biologic agents as second-line therapy of advanced thyroid cancer. Oncology 2013, 18, 1262-1269. [CrossRef] [PubMed]

5. Raue, F.; Frank-Raue, K. Thyroid cancer: Risk-stratified management and individualized therapy. Clin. Cancer Res. Off. J. Am. Assoc. Cancer Res. 2016, 22, 5012-5021. [CrossRef] [PubMed]

6. Ibrahimpasic, T.; Ghossein, R.; Shah, J.P.; Ganly, I. Poorly differentiated carcinoma of the thyroid gland: Current status and future prospects. Thyroid Off. J. Am. Thyroid Assoc. 2019, 29, 311-321. [CrossRef] [PubMed]

7. De Castroneves, L.A.; Negrao, M.V.; de Freitas, R.M.; Papadia, C.; Lima, J.V., Jr.; Fukushima, J.T.; Simao, E.F.; Kulcsar, M.A.; Tavares, M.R.; Jorge, A.A.; et al. Sorafenib for the treatment of progressive metastatic medullary thyroid cancer: Efficacy and safety analysis. Thyroid Off. J. Am. Thyroid Assoc. 2016, 26, 414-419. [CrossRef]

8. Ito, Y.; Onoda, N.; Ito, K.I.; Sugitani, I.; Takahashi, S.; Yamaguchi, I.; Kabu, K.; Tsukada, K. Sorafenib in japanese patients with locally advanced or metastatic medullary thyroid carcinoma and anaplastic thyroid carcinoma. Thyroid Off. J. Am. Thyroid Assoc. 2017, 27, 1142-1148. [CrossRef]

9. Ozaki, T.; Yu, M.; Yin, D.; Sun, D.; Zhu, Y.; Bu, Y.; Sang, M. Impact of runx2 on drug-resistant human pancreatic cancer cells with p53 mutations. BMC Cancer 2018, 18, 309. [CrossRef]

10. He, Y. Systematic response of staurosporine scaffold-based inhibitors to drug-resistant cancer kinase mutations. Arch. Der Pharm. 2020, 353, e1900320. [CrossRef]

11. Smith, B.D.; Kaufman, M.D.; Lu, W.P.; Gupta, A.; Leary, C.B.; Wise, S.C.; Rutkoski, T.J.; Ahn, Y.M.; Al-Ani, G.; Bulfer, S.L.; et al Ripretinib (dcc-2618) is a switch control kinase inhibitor of a broad spectrum of oncogenic and drug-resistant kit and pdgfra variants. Cancer Cell 2019, 35, 738-751.e739. [CrossRef]

12. Cao, X.; Hou, J.; An, Q.; Assaraf, Y.G.; Wang, X. Towards the overcoming of anticancer drug resistance mediated by p53 mutations. Drug Resist. Updates Rev. Comment. Antimicrob. Anticancer Chemother. 2020, 49, 100671. [CrossRef]

13. Liu, Q.; Yu, S.; Zhao, W.; Qin, S.; Chu, Q.; Wu, K. Egfr-tkis resistance via egfr-independent signaling pathways. Mol. Cancer 2018, 17, 53. [CrossRef]

14. Hientz, K.; Mohr, A.; Bhakta-Guha, D.; Efferth, T. The role of p53 in cancer drug resistance and targeted chemotherapy. Oncotarget 2017, 8, 8921-8946. [CrossRef] [PubMed]

15. Liu, J.; Liu, Y.; Lin, Y.; Liang, J. Radioactive iodine-refractory differentiated thyroid cancer and redifferentiation therapy. Endocrinol. Metab. 2019, 34, 215-225. [CrossRef]

16. Brose, M.S.; Cabanillas, M.E.; Cohen, E.E.; Wirth, L.J.; Riehl, T.; Yue, H.; Sherman, S.I.; Sherman, E.J. Vemurafenib in patients with braf(v600e)-positive metastatic or unresectable papillary thyroid cancer refractory to radioactive iodine: A non-randomised, multicentre, open-label, phase 2 trial. Lancet Oncol. 2016, 17, 1272-1282. [CrossRef]

17. Miftari, R.; Topciu, V.; Nura, A.; Haxhibeqiri, V. Management of the patient with aggressive and resistant papillary thyroid carcinoma. Med. Arch. 2016, 70, 314-317. [CrossRef]

18. Grygielewicz, P.; Dymek, B.; Bujak, A.; Gunerka, P.; Stanczak, A.; Lamparska-Przybysz, M.; Wieczorek, M.; Dzwonek, K.; Zdzalik, D. Epithelial-mesenchymal transition confers resistance to selective fgfr inhibitors in snu- 16 gastric cancer cells. Gastric Cancer Off. J. Int. Gastric Cancer Assoc. Jpn. Gastric Cancer Assoc. 2016, 19, 53-62. [CrossRef] [PubMed] 
19. Housman, G.; Byler, S.; Heerboth, S.; Lapinska, K.; Longacre, M.; Snyder, N.; Sarkar, S. Drug resistance in cancer: An overview. Cancers 2014, 6, 1769-1792. [CrossRef] [PubMed]

20. Wang, Y.; Shi, J.; Chai, K.; Ying, X.; Zhou, B.P. The role of snail in emt and tumorigenesis. Curr. Cancer Drug Targets 2013, 13, 963-972. [CrossRef]

21. Gloushankova, N.A.; Rubtsova, S.N.; Zhitnyak, I.Y. Cadherin-mediated cell-cell interactions in normal and cancer cells. Tissue Barriers 2017, 5, e1356900. [CrossRef]

22. Stuhlmiller, T.J.; Miller, S.M.; Zawistowski, J.S.; Nakamura, K.; Beltran, A.S.; Duncan, J.S.; Angus, S.P.; Collins, K.A.; Granger D.A.; Reuther, R.A.; et al. Inhibition of lapatinib-induced kinome reprogramming in erbb2-positive breast cancer by targeting bet family bromodomains. Cell Rep. 2015, 11, 390-404. [CrossRef] [PubMed]

23. D'Amato, V.; Raimondo, L.; Formisano, L.; Giuliano, M.; De Placido, S.; Rosa, R.; Bianco, R. Mechanisms of lapatinib resistance in her2-driven breast cancer. Cancer Treat. Rev. 2015, 41, 877-883. [CrossRef] [PubMed]

24. Otte, J.; Dizdar, L.; Behrens, B.; Goering, W.; Knoefel, W.T.; Wruck, W.; Stoecklein, N.H.; Adjaye, J. Fgf signalling in the self-renewal of colon cancer organoids. Sci. Rep. 2019, 9, 17365. [CrossRef] [PubMed]

25. Dong, P.; Konno, Y.; Watari, H.; Hosaka, M.; Noguchi, M.; Sakuragi, N. The impact of microrna-mediated pi3k/akt signaling on epithelial-mesenchymal transition and cancer stemness in endometrial cancer. J. Transl. Med. 2014, 12, 231. [CrossRef]

26. Garg, M. Urothelial cancer stem cells and epithelial plasticity: Current concepts and therapeutic implications in bladder cancer. Cancer Metastasis Rev. 2015, 34, 691-701. [CrossRef]

27. Brown, W.S.; Akhand, S.S.; Wendt, M.K. Fgfr signaling maintains a drug persistent cell population following epithelialmesenchymal transition. Oncotarget 2016, 7, 83424-83436. [CrossRef]

28. Yang, L.; Shi, P.; Zhao, G.; Xu, J.; Peng, W.; Zhang, J.; Zhang, G.; Wang, X.; Dong, Z.; Chen, F.; et al. Targeting cancer stem cell pathways for cancer therapy. Signal Transduct Target 2020, 5, 8. [CrossRef]

29. Kweon, S.S.; Shin, M.H.; Chung, I.J.; Kim, Y.J.; Choi, J.S. Thyroid cancer is the most common cancer in women, based on the data from population-based cancer registries, South Korea. Jpn. J. Clin. Oncol. 2013, 43, 1039-1046. [CrossRef]

30. Cabanillas, M.E.; McFadden, D.G.; Durante, C. Thyroid cancer. Lancet 2016, 388, 2783-2795. [CrossRef]

31. Kim, J.; Gosnell, J.E.; Roman, S.A. Geographic influences in the global rise of thyroid cancer. Nat. Rev. Endocrinol. 2020, 16, 17-29. [CrossRef]

32. Prete, A.; Borges de Souza, P.; Censi, S.; Muzza, M.; Nucci, N.; Sponziello, M. Update on fundamental mechanisms of thyroid cancer. Front. Endocrinol. 2020, 11, 102. [CrossRef] [PubMed]

33. Wiltshire, J.J.; Drake, T.M.; Uttley, L.; Balasubramanian, S.P. Systematic review of trends in the incidence rates of thyroid cancer. Thyroid Off. J. Am. Thyroid Assoc. 2016, 26, 1541-1552. [CrossRef]

34. Pellegriti, G.; De Vathaire, F.; Scollo, C.; Attard, M.; Giordano, C.; Arena, S.; Dardanoni, G.; Frasca, F.; Malandrino, P.; Vermiglio, F.; et al. Papillary thyroid cancer incidence in the volcanic area of sicily. J. Natl. Cancer Inst. 2009, 101, 1575-1583. [CrossRef] [PubMed]

35. Bergdorf, K.; Ferguson, D.C.; Mehrad, M.; Ely, K.; Stricker, T.; Weiss, V.L. Papillary thyroid carcinoma behavior: Clues in the tumor microenvironment. Endocr.-Relat. Cancer 2019, 26, 601-614. [CrossRef]

36. Lewinski, A.; Adamczewski, Z. Papillary thyroid carcinoma: A cancer with an extremely diverse genetic background and prognosis. Pol. Arch. Intern. Med. 2017, 127, 388-389. [CrossRef]

37. Colombo, C.; Minna, E.; Gargiuli, C.; Muzza, M.; Dugo, M.; De Cecco, L.; Pogliaghi, G.; Tosi, D.; Bulfamante, G.; Greco, A.; et al. The molecular and gene/mirna expression profiles of radioiodine resistant papillary thyroid cancer. J. Exp. Clin. Cancer Res. CR 2020, 39, 245. [CrossRef] [PubMed]

38. Zelinskaya, A. Immunocytochemical characteristics of thyrocytes in radioiodine refractory metastases of papillary thyroid cancer. Exp. Oncol. 2019, 41, 342-345. [CrossRef]

39. Stassi, G.; Todaro, M.; Zerilli, M.; Ricci-Vitiani, L.; Di Liberto, D.; Patti, M.; Florena, A.; Di Gaudio, F.; Di Gesu, G.; De Maria, R Thyroid cancer resistance to chemotherapeutic drugs via autocrine production of interleukin-4 and interleukin-10. Cancer Res. 2003, 63, 6784-6790.

40. Giuffrida, R.; Adamo, L.; Iannolo, G.; Vicari, L.; Giuffrida, D.; Eramo, A.; Gulisano, M.; Memeo, L.; Conticello, C. Resistance of papillary thyroid cancer stem cells to chemotherapy. Oncol. Lett. 2016, 12, 687-691. [CrossRef]

41. Jemal, A.; Siegel, R.; Ward, E.; Murray, T.; Xu, J.; Thun, M.J. Cancer statistics, 2007. CA Cancer J. Clin. 2007, 57, 43-66. [CrossRef] [PubMed]

42. Davies, L.; Welch, H.G. Increasing incidence of thyroid cancer in the United States, 1973-2002. JAMA 2006, $295,2164-2167$. [CrossRef] [PubMed]

43. De Groot, J.W.; Links, T.P.; Plukker, J.T.; Lips, C.J.; Hofstra, R.M. Ret as a diagnostic and therapeutic target in sporadic and hereditary endocrine tumors. Endocr. Rev. 2006, 27, 535-560. [CrossRef]

44. Kondo, T.; Ezzat, S.; Asa, S.L. Pathogenetic mechanisms in thyroid follicular-cell neoplasia. Nat. Rev. Cancer 2006, 6, 292-306. [CrossRef]

45. Smallridge, R.C.; Marlow, L.A.; Copland, J.A. Anaplastic thyroid cancer: Molecular pathogenesis and emerging therapies Endocr.-Relat. Cancer 2009, 16, 17-44. [CrossRef] [PubMed]

46. Ivan, M.; Bond, J.A.; Prat, M.; Comoglio, P.M.; Wynford-Thomas, D. Activated ras and ret oncogenes induce over-expression of c-met (hepatocyte growth factor receptor) in human thyroid epithelial cells. Oncogene 1997, 14, 2417-2423. [CrossRef] [PubMed] 
47. Salvatore, D.; Barone, M.V.; Salvatore, G.; Melillo, R.M.; Chiappetta, G.; Mineo, A.; Fenzi, G.; Vecchio, G.; Fusco, A.; Santoro, M. Tyrosines 1015 and 1062 are in vivo autophosphorylation sites in ret and ret-derived oncoproteins. J. Clin. Endocrinol. Metab. 2000, 85, 3898-3907.

48. Wilson, M.M.; Weinberg, R.A.; Lees, J.A.; Guen, V.J. Emerging mechanisms by which emt programs control stemness. Trends Cancer 2020, 6, 775-780. [CrossRef]

49. Miyoshi, N.; Haraguchi, N.; Mizushima, T.; Ishii, H.; Yamamoto, H.; Mori, M. Targeting cancer stem cells in refractory cancer. Regen. Ther. 2021, 17, 13-19. [CrossRef]

50. Fujita, Y.; Kojima, K.; Ohhashi, R.; Hamada, N.; Nozawa, Y.; Kitamoto, A.; Sato, A.; Kondo, S.; Kojima, T.; Deguchi, T.; et al Mir-148a attenuates paclitaxel resistance of hormone-refractory, drug-resistant prostate cancer pc3 cells by regulating msk1 expression. J. Biol. Chem. 2010, 285, 19076-19084. [CrossRef]

51. Oien, D.B.; Pathoulas, C.L.; Ray, U.; Thirusangu, P.; Kalogera, E.; Shridhar, V. Repurposing quinacrine for treatment-refractory cancer. Semin. Cancer Biol. 2021, 68, 21-30. [CrossRef] [PubMed]

52. Lu, W.; Kang, Y. Epithelial-mesenchymal plasticity in cancer progression and metastasis. Dev. Cell 2019, 49, 361-374. [CrossRef]

53. Tsubakihara, Y.; Moustakas, A. Epithelial-mesenchymal transition and metastasis under the control of transforming growth factor beta. Int. J. Mol. Sci. 2018, 19, 3672. [CrossRef] [PubMed]

54. Vicari, L.; Colarossi, C.; Giuffrida, D.; De Maria, R.; Memeo, L. Cancer stem cells as a potential therapeutic target in thyroid carcinoma. Oncol. Lett. 2016, 12, 2254-2260. [CrossRef] [PubMed]

55. Guo, Z.; Hardin, H.; Lloyd, R.V. Cancer stem-like cells and thyroid cancer. Endocr.-Relat. Cancer 2014, 21, T285-T300. [CrossRef] [PubMed]

56. Borah, A.; Raveendran, S.; Rochani, A.; Maekawa, T.; Kumar, D.S. Targeting self-renewal pathways in cancer stem cells: Clinical implications for cancer therapy. Oncogenesis 2015, 4, e177. [CrossRef]

57. Sarkar, F.H.; Li, Y.; Wang, Z.; Kong, D. Pancreatic cancer stem cells and emt in drug resistance and metastasis. Minerva Chir. 2009, $64,489-500$.

58. Singh, A.; Settleman, J. Emt, cancer stem cells and drug resistance: An emerging axis of evil in the war on cancer. Oncogene 2010, 29, 4741-4751. [CrossRef]

59. Lee, Y.S.; Kim, S.M.; Kim, B.W.; Chang, H.J.; Kim, S.Y.; Park, C.S.; Park, K.C.; Chang, H.S. Anti-cancer effects of hnha and lenvatinib by the suppression of emt-mediated drug resistance in cancer stem cells. Neoplasia 2018, 20, 197-206. [CrossRef]

60. Du, B.; Shim, J.S. Targeting epithelial-mesenchymal transition (emt) to overcome drug resistance in cancer. Molecules 2016, 21(7), 965. [CrossRef] [PubMed]

61. Chang, J.C. Cancer stem cells: Role in tumor growth, recurrence, metastasis, and treatment resistance. Medicine 2016, 95, S20-S25. [CrossRef] [PubMed]

62. Phi, L.T.H.; Sari, I.N.; Yang, Y.G.; Lee, S.H.; Jun, N.; Kim, K.S.; Lee, Y.K.; Kwon, H.Y. Cancer stem cells (cscs) in drug resistance and their therapeutic implications in cancer treatment. Stem Cells Int. 2018, 2018. [CrossRef] [PubMed]

63. Kroemer, G. The proto-oncogene bcl-2 and its role in regulating apoptosis. Nat. Med. 1997, 3, 614-620. [CrossRef] [PubMed]

64. Greenberg, E.F.; Lavik, A.R.; Distelhorst, C.W. Bcl-2 regulation of the inositol 1,4,5-trisphosphate receptor and calcium signaling in normal and malignant lymphocytes: Potential new target for cancer treatment. Biochim. Biophys. Acta 2014, 1843, 2205-2210. [CrossRef]

65. An, J.; Lv, J.; Li, A.; Qiao, J.; Fang, L.; Li, Z.; Li, B.; Zhao, W.; Chen, H.; Wang, L. Constitutive expression of bcl-2 induces epithelial-mesenchymal transition in mammary epithelial cells. BMC Cancer 2015, 15, 476. [CrossRef] [PubMed]

66. Garrido, C.; Galluzzi, L.; Brunet, M.; Puig, P.E.; Didelot, C.; Kroemer, G. Mechanisms of cytochrome c release from mitochondria Cell Death Differ. 2006, 13, 1423-1433. [CrossRef]

67. Morales-Cruz, M.; Figueroa, C.M.; Gonzalez-Robles, T.; Delgado, Y.; Molina, A.; Mendez, J.; Morales, M.; Griebenow, K. Activation of caspase-dependent apoptosis by intracellular delivery of cytochrome c-based nanoparticles. J. Nanobiotechnol. 2014, 12, 33. [CrossRef]

68. Lim, J.H.; Choi, K.H.; Kim, S.Y.; Park, C.S.; Kim, S.M.; Park, K.C. Patient-derived, drug-resistant colon cancer cells evade chemotherapeutic drug effects via the induction of epithelial-mesenchymal transition-mediated angiogenesis. Int. J. Mol. Sci. 2020, 21, 7469. [CrossRef]

69. Han, J.Y.; Ahn, K.S.; Kim, T.S.; Kim, Y.H.; Cho, K.B.; Shin, D.W.; Baek, W.K.; Suh, S.I.; Jang, B.C.; Kang, K.J. Liquid biopsy from bile-circulating tumor DNA in patients with biliary tract cancer. Cancers 2021, 13, 4581. [CrossRef]

70. Kim, S.M.; Kim, S.Y.; Park, C.S.; Chang, H.S.; Park, K.C. Impact of age-related genetic differences on the therapeutic outcome of papillary thyroid cancer. Cancers 2020, 12, 448. [CrossRef] 